\title{
Mn-alginate gels as a novel system for controlled release of $\mathrm{Mn}^{2+}$ in manganese- enhanced MRI
}

\author{
Ýrr A. Mørch ${ }^{a *}$, loanna Sandvig ${ }^{b}, \varnothing$ stein Olsen ${ }^{c}$, Ivan Donati ${ }^{d}$, \\ Marte Thuen ${ }^{b}$, Gudmund Skjåk-Bræk ${ }^{a}$, Olav Haraldseth ${ }^{b, e}$ and \\ Christian Brekken ${ }^{\text {b }}$
}

The aim of the present study was to test alginate gels of different compositions as a system for controlled release of manganese ions $\left(\mathrm{Mn}^{2+}\right)$ for application in manganese-enhanced MRI (MEMRI), in order to circumvent the challenge of achieving optimal MRI resolution without resorting to high, potentially cytotoxic doses of $\mathrm{Mn}^{2+}$. Elemental analysis and stability studies of $\mathrm{Mn}$-alginate revealed marked differences in ion binding capacity, rendering $\mathrm{Mn} / \mathrm{Ba}$-alginate gels with high guluronic acid content most stable. The findings were corroborated by corresponding differences in the release rate of $\mathrm{Mn}^{2+}$ from alginate beads in vitro using $T_{1}$-weighted MRI. Furthermore, intravitreal (ivit) injection of Mn-alginate beads yielded significant enhancement of the rat retina and retinal ganglion cell (RGC) axons $24 \mathrm{~h}$ post-injection. Subsequent compartmental modelling and simulation of ivit $\mathrm{Mn}^{2+}$ transport and concentration revealed that application of slow release contrast agents can achieve a significant reduction of ivit $\mathrm{Mn}^{2+}$ concentration compared with bolus injection. This is followed by a concomitant increase in the availability of ivit $\mathrm{Mn}^{2+}$ for uptake by RGC, corresponding to significantly increased time constants. Our results provide proof-of-concept for the applicability of $\mathrm{Mn}$-alginate gels as a system for controlled release of $\mathrm{Mn}^{2+}$ for optimized MEMRI application. Copyright $\odot 2012$ John Wiley \& Sons, Ltd.

Keywords: alginate; manganese-enhanced MRl; controlled release; optic nerve; intravitreal injection; ion-binding; retina; retinal ganglion cell axons

\section{INTRODUCTION}

Alginate, an unbranched polysaccharide composed of guluronic (G) and mannuronic acid (M), is widely used in medicine owing to its unique ability to form a gel at physiological conditions in the presence of divalent cations like $\mathrm{Ca}^{2+}, \mathrm{Ba}^{2+}$ and $\mathrm{Mn}^{2+}$. In the polymer chain, the monomers are arranged in a block-wise manner as GG-blocks, MG-blocks or MM-blocks of various lengths. Although the importance of G-blocks in the gel-forming process is widely acknowledged, more recent studies (1-3) have shown that the MG-blocks also play an important role in the formation of stable hydrogels. Hence, the gelling properties of alginates are highly dependent on the total composition and arrangement of the monomers in the polymer chains. However, as alginate's affinity to divalent ions differs greatly [in the order $\mathrm{Ba}>\mathrm{Ca}>>\mathrm{Mn}$ for naturally occurring alginates $(4,5)]$, the choice of ions is also of utmost importance (6). It is well known that the binding between guluronic acid residues and $\mathrm{Ca}$ or $\mathrm{Ba}$ ions is characterized by strong and specific autocooperativity (7). On the other hand, the binding between uronic acid residues in alginate and transition metals like $\mathrm{Mn}$ has been characterized by a complex formation in which only the carboxyl groups are coordinated to the metal ions (8).

lonically crosslinked alginate hydrogels tend to swell and dissolve at physiological conditions mainly caused by the gel network sensitivity towards chelating compounds and/or nongelling cations such as sodium and magnesium. The divalent crosslinking ions will be released in competition with non-gelling ions, dissolving the junctions in the network. At the same time, given the different valence of crosslinking ions (e.g. $\mathrm{Ca}^{2+}, \mathrm{Ba}^{2+}$ ) and $\mathrm{Na}^{+}$, each divalent ion will be replaced with two $\mathrm{Na}^{+}$, thus increasing the osmotic pressure within the gel network. Both of these effects contribute to swelling and destabilization of the hydrogel network. Swelling can be reduced by using alginate

\footnotetext{
* Correspondence to: Ýrr A. Mørch, Department of Biotechnology, NTNU, Sem Sælands vei 6/8, NO-7491 Trondheim, Norway.

E-mail: yrr.morch@ntnu.no

a Ý. A. Mørch, G. Skjåk-Bræk Department of Biotechnology, Norwegian University of Science and Technology, Trondheim, Norway

b I. Sandvig, M. Thuen, O. Haraldseth, C. Brekken MI Lab and Department of Circulation and Medical Imaging, Norwegian University of Science and Technology, Trondheim, Norway

c Ø. Olsen

Department of Technology, Sør-Trøndelag University College, Trondheim, Norway

d I. Donati

Department of Biochemistry, Biophysics and Macromolecular Chemistry, University of Trieste, Trieste, Italy

e O. Haraldseth

Department of Radiology, St Olav's Hospital, Trondheim, Norway
} 
with a high content of long guluronic acid blocks $(9,10)$, or by using divalent ions with high binding affinity to alginate (such as $\mathrm{Ba}^{2+}$ ) (10-12). As manganese has low affinity to alginate and consequently does not form stable hydrogels, a limited amount of research has been dedicated to $\mathrm{Mn}$-alginate gels. Conversely, we hypothesize that this lack of stability may be used for the purpose of a slow release system of $\mathrm{Mn}^{2+}$ for magnetic resonance imaging.

Manganese-enhanced magnetic resonance imaging (MEMRI) is an imaging modality that utilizes the unique properties of manganese ions $\left(\mathrm{Mn}^{2+}\right)$ as an intracellular and functional contrast agent in $T_{1}$-weighted imaging. In the central nervous system (CNS), $\mathrm{Mn}^{2+}$ enter neurons through L-type voltage-gated $\mathrm{Ca}^{2+}$ channels (13), after either systemic delivery or direct injection into the area of interest. Furthermore, $\mathrm{Mn}^{2+}$ are paramagnetic and shorten the $T_{1}$ spin-lattice relaxation time of surrounding water protons in areas of $\mathrm{Mn}^{2+}$ accumulation, yielding high-contrast $T_{1}$-weighted MR images (14-16). Given these properties and the fact that various brain tissues, such as the different cortical laminae, display different $\mathrm{Mn}^{2+}$ affinity, $\mathrm{Mn}^{2+}$ can be utilized as a contrast agent in studies of neuronal architecture (17). Furthermore, increased brain activity results in elevated intracellular uptake of $\mathrm{Mn}^{2+}$ via $\mathrm{Ca}^{2+}$ channels. As a result, MEMRI can also be utilized in studies of functional brain activity $(18,19)$. In addition to the above, MEMRI can be used for in vivo tracing of CNS axon tracts $(15,17,20-22)$. Upon entry into neurons, $\mathrm{Mn}^{2+}$ are sequestered in the endoplasmic reticulum, and subsequently transported along axonal microtubules to the synaptic cleft, where they are released and trans-synaptically relayed to other neurons $(15,20,23)$. The specific properties of $\mathrm{Mn}^{2+}$ render MEMRI particularly relevant in experimental models of CNS damage and repair, as it enables longitudinal monitoring of damaged and regenerating neuronal pathways $(21,22,24,25)$ and connectivity in vivo (26-28).

Nevertheless, a major consideration in applying MEMRI is the potential risk of $\mathrm{Mn}^{2+}$-induced cytotoxicity (29) associated with high and/or repeated doses of $\mathrm{Mn}^{2+}$. Previous studies demonstrated that increased $\mathrm{Mn}^{2+}$-induced signal enhancement, which is desirable in terms of optimal image resolution, can be obtained with higher doses of $\mathrm{Mn}^{2+}$ (30), followed by the caveat that neuronal viability may be significantly compromised $(21,31,32)$. It has been demonstrated, though, that there is a plateau of maximum $\mathrm{Mn}^{2+}$ entry into neurons, which indicates that increased $\mathrm{Mn}^{2+}$-induced signal enhancement is contingent on the duration of $\mathrm{Mn}^{2+}$ availability, rather than on $\mathrm{Mn}^{2+}$ dose (30). It follows that regulation and adjustment of $\mathrm{Mn}^{2+}$ release to the neuronal uptake threshold should dramatically reduce exposure of neurons to $\mathrm{Mn}^{2+}$, a manipulation that should be possible with the use of tailor-made alginate matrices saturated with $\mathrm{Mn}^{2+}$ for targeted, controlled release of $\mathrm{Mn}^{2+}$.

The purpose of this study was to analyse the binding and release of manganese ions from different types of alginate gels. We aimed to design a system for slow and controlled release of $\mathrm{Mn}^{2+}$ as a contrast agent in MRI. The release of manganese from alginate gels using two commercial alginates (a high-M and high-G alginate) as well as alginates of extreme composition (polyM, polyMG and polyG alginate) and different combinations of divalent ions was studied. $\mathrm{Mn}^{2+}$ release from single alginate beads in vitro was imaged in real time using $T_{1}$-weighted MRI at $7 \mathrm{~T}$ and relevant time constants were obtained. Furthermore, ivit injection of $\mathrm{Mn}$-alginate beads in rat was performed to obtain MEMRI of the rat retina, optic nerve and contralateral superior colliculus at $2.35 \mathrm{~T}$, thus providing proof-of-concept regarding the utility of Mn-alginate gels for controlled release of $\mathrm{Mn}^{2+}$ for MEMRI.

\section{MATERIALS AND METHODS}

\subsection{Alginates}

Five different alginate samples were used in the present study. Two commercially available alginates and three alginates of extreme composition representing the different blocks in alginate were obtained from FMC biopolymer and Sigma Chemicals, respectively: (i) high-G alginate from Laminaria hyperborea (67\% $\mathrm{G}$, intrinsic viscosity $620 \mathrm{ml} \mathrm{g}^{-1}$ ) and (ii) high-M alginate from Macrocystis pyrifera ( $40 \% \mathrm{G}$, intrinsic viscosity $820 \mathrm{mlg}^{-1}$ ). (iii) $\mathrm{A}$ polymannuronan alginate (polyM, 0\% G, intrinsic viscosity $800 \mathrm{mlg}^{-1}$ ) was produced by an epimerase-negative mutant (AlgG $^{-}$) of Pseudomonas fluorescens (33). (iv) A strictly alternating (polyMG) alginate (46\% G, 0\% GG, intrinsic viscosity $700 \mathrm{ml} \mathrm{g}^{-1}$ ) and (v) a polyguluronan alginate (polyG, $88 \% \mathrm{G}$, intrinsic viscosity $1150 \mathrm{ml} \mathrm{g}^{-1}$ ) were achieved by epimerizing the bacterial polyM alginate with the $\mathrm{C}-5$ epimerases AlgE4 and AlgE6, respectively, as reported elsewhere (34). For circular dichroism (CD) measurements, the polyG sample used was an acid-insoluble fraction of alginate (35) enriched in G blocks ( $94 \% \mathrm{G})$ with a degree of polymerization (DPn) of 18.5 .

\subsection{Alginate gel beads}

Alginate gel beads were formed by dripping a $1.8 \%(\mathrm{w} / \mathrm{v})$ solution of Na-alginate (filtered through $0.8 \mu \mathrm{m}$ filters, dissolved in ion free water) into solutions containing divalent cations (gelling solutions). The solutions contained $0.1 \mathrm{M} \mathrm{MnCl}_{2}+1 \mathrm{mM} \mathrm{BaCl} 2$ or $0.1 \mathrm{M} \mathrm{MnCl}_{2}+10 \mathrm{~mm} \mathrm{CaCl}$. A syringe pump was utilized in order to form evenly sized, spherical beads.

\subsection{Alginate gel cylinders}

Alginate samples $(1.8 \% \mathrm{w} / \mathrm{v})$ were placed into hollow plastic cylinders (inner diameter, $16 \mathrm{~mm}$; height, $18 \mathrm{~mm}$ ) with a dialysis membrane (MWCO 12 000-14 000) attached at both ends. The cylinders were kept in gelling solution $\left(0.1 \mathrm{M} \mathrm{MnCl}_{2}+1 \mathrm{~mm} \mathrm{BaCl} 2\right.$ or $0.1 \mathrm{M} \mathrm{MnCl}_{2}+10 \mathrm{~mm} \mathrm{CaCl}$ ) for $48 \mathrm{~h}$.

\subsection{Elemental analysis}

Alginate beads were gelled in solutions containing the various amounts of divalent ions for $24 \mathrm{~h}$, and washed three times in saline $(<1 \mathrm{~min})$ to remove excess ions. The beads were dried gently on a paper cloth and placed in polylpropylene tubes $(60 \mathrm{ml}$, Sarstedt) before tri-Na-citrate $(50 \mathrm{~mm}$, Merck) was added to dissolve the gels. Elemental analysis was performed by inductively coupled plasma mass spectrometry (High-resolution ICP-MS, Element 2, Thermo Scientific) to measure the content of $\mathrm{Mn}, \mathrm{Ba}$ and $\mathrm{Ca}$ in the gel after dissolution in Na citrate. The stability of the different gels towards ion-exchange (and hence $\mathrm{Mn}^{2+}$ release) was studied by monitoring the dimensional swelling of the gel beads upon incubations in saline $(0.9 \% \mathrm{NaCl})$. The saline solution was changed every hour.

\subsection{Circular dichroism spectroscopy}

Circular dichroic spectra of the sodium form of polyM, polyG and polyMG $\left(c \approx 3 \times 10^{-3}\right.$ monomol $\left.I^{-1}\right)$ were recorded in deionized 
water with an Olis DSM 1000 spectropolarimeter. A quartz cell of $1 \mathrm{~cm}$ optical path length was used. The integration time was a function of high voltage, and bandwidth was $1 \mathrm{~nm}$. Four spectra corrected for the background were averaged for each sample. The spectrum of each sample was recorded prior to and after the addition of $\mathrm{Mn}\left(\mathrm{ClO}_{4}\right)_{2}$, with an increasing $\left[\mathrm{Mn}^{2+}\right] /[$ Polym $r u]$ (Rj) ratio.

\subsection{Viscosity measurements}

Specific capillary viscosity was measured at $25^{\circ} \mathrm{C}$ by means of a Schott-Geräte AVS/G automatic apparatus and an Ubbelohde type viscometer upon addition of $\mathrm{Mg}\left(\mathrm{ClO}_{4}\right)_{2}, \mathrm{Mn}\left(\mathrm{ClO}_{4}\right)_{2}$ and $\mathrm{Ca}$ $\left(\mathrm{ClO}_{4}\right)_{2}$ at different values of the $R_{j}$ ratio $\left(R_{j}=\left[\mathrm{M}^{2+}\right] / \mathrm{Cp}\right)$. A $3 \times 10^{-3}$ monomol I ${ }^{-1}$ polymer solution $(C p)$ in $0.05 \mathrm{M} \mathrm{NaClO}_{4}$ was used in all cases. All solutions were filtered through Millipore filters $(0.45 \mu \mathrm{m})$ prior to use.

\subsection{In vitro $\mathrm{MRI}$ of $\mathrm{Mn}^{2+}$ release from single alginate beads}

MRI was performed at 7T on a Bruker Biospec 70/20 AS with BGA-12 $400 \mathrm{mT} \mathrm{m}^{-1}$ gradients. A $72 \mathrm{~mm}$ volume resonator was used for RF transmit and receive. Single alginate beads (diameter approximately $4 \mathrm{~mm}$ ) stored in gelling solution were rapidly ( $<1 \mathrm{~min}$ ) washed three times in $3 \mathrm{ml} 0.9 \% \mathrm{NaCl}$ and suspended by a nylon tulle sling inside empty $5 \mathrm{ml}$ glass vials connected to a custom-made fluid-transfer line. The glass vials with the alginate beads were subsequently placed inside the scanner. The MRI protocol consisted of tri-axial 2D scout scans, and an evolutionary $2 \mathrm{D} T_{1}$-weighted sequence up to $24 \mathrm{~h}$ after alginate bead immersion into $5 \mathrm{ml} 0.9 \% \mathrm{NaCl}$ solution inside the magnet via the above-mentioned fluid-transfer line. The specific protocol was repeated three times for each type of alginate bead. Key parameters for MRI included:

- 2D MSME $\left(T_{1}\right)$ scout scan: echo time, $11 \mathrm{~ms}$; repetition time, $200 \mathrm{~ms}$; field of view, $50 \times 50 \mathrm{~mm}$; matrix, $128 \times 128$; slice thickness, $1 \mathrm{~mm}$ (three orthogonal slices); number of excitations, 1; acquisition time, $25 \mathrm{~s}$.

- 2D MSME $\left(T_{1}\right)$ evolution scanning: echo time, $8.1 \mathrm{~ms}$; repetition time, $500 \mathrm{~ms}$; field of view, $30 \times 40 \mathrm{~mm}$; matrix, $128 \times 64$; slice thickness, $1 \mathrm{~mm}$; number of excitations, 1 ; six frames per hour during $24 \mathrm{~h}$.

\subsection{In vivo $\mathrm{MRI}$ of $\mathrm{Mn}^{2+}$ release from alginate beads}

All experimental procedures involving animals were approved by the appropriate ethics committee and were in accordance with national, regional and site guidelines that apply. During surgery and in vivo $\mathrm{MRI}$, rats were anesthetized with a 1:1:2 mixture of Hypnorm-Durmicum-sterile water subcutaneously $\left(2.5 \mathrm{ml} \mathrm{kg}^{-1}\right)$. Small high-G Mn-alginate beads (diameter approximately $500 \mu \mathrm{m})$ were formed by dripping a $1.8 \%(\mathrm{w} / \mathrm{v})$ alginate solution into a $1 \mathrm{M} \mathrm{MnCl}_{2}+1 \mathrm{~mm} \mathrm{BaCl} 2$ gelling solution using an electrostatic bead generator. Approximately 20 beads were unilaterally implanted into the vitreous body of adult Fischer rats $(n=4)$ through the ora serrata using a $25 \mathrm{G}$ needle. MRI was performed $24 \mathrm{~h}$ after alginate bead implantation using a $2.35 \mathrm{~T}$ Bruker Biospec Avance DBX-100 (Bruker Biospin) with a $72 \mathrm{~mm}$ volume coil for transmission and an actively decoupled rat head surface coil for receive-only. Anesthetized rats lay prone in a dedicated animal bed heated with warm air at $37{ }^{\circ} \mathrm{C}$. After acquiring a scout scan, a 3D data set of the entire rat head was obtained using a $T_{1}$-weighted 3D low-flip-angle shot (FLASH) gradient echo sequence with echo time, $4.2 \mathrm{~ms}$; repetition time, $15 \mathrm{~ms}$; flip angle, $25^{\circ}$; field of view, $50 \times 50 \times 20 \mathrm{~mm}^{3}$; matrix, $256 \times 256 \times 64$ (resolution, $195 \times 105 \times 312 \mu \mathrm{m}^{3}$ ) with eight averages and a total scan time of $33 \mathrm{~min}$

\subsection{Model of $\mathrm{Mn}^{2+}$ release and analysis of MRI data}

A compartment model of the system (Fig. 1A) was used to describe the release of $\mathrm{Mn}^{2+}$ from the dissolving alginate beads and the subsequent increase in $\mathrm{Mn}^{2+}$ concentration in the surrounding physiological saline solution. Under the assumption of mass conservation, the rate of change of the amount of bound $\mathrm{Mn}^{2+}$ in the alginate gel beads was described by:

$$
\frac{\mathrm{d} Q_{1}}{\mathrm{~d} t}=-k_{1} Q_{1}, \quad Q_{1}(0)=Q_{01}
$$

where $Q_{1}$ is the time dependent amount of bound $\mathrm{Mn}^{2+}, k_{1}$ the release rate coefficient and $Q_{01}$ the initial amount of bound $\mathrm{Mn}^{2+}$ in the alginate gel beads. The rate of change of the amount of unbound $\mathrm{Mn}^{2+}$ was described by:

$$
\frac{\mathrm{d} Q_{2}}{\mathrm{~d} t}=-k_{2} Q_{2}, \quad Q_{2}(0)=Q_{02}
$$

where $Q_{2}$ is the time-dependent amount of unbound $\mathrm{Mn}^{2+}, k_{2}$ the release rate coefficient and $Q_{02}$ the initial amount of unbound $\mathrm{Mn}^{2+}$ in the alginate gel beads. The rate of change of the amount of $\mathrm{Mn}^{2+}$ in the saline solution, $Q_{3}$, surrounding the alginate gels during the MR experiment, was described by:

\section{A}

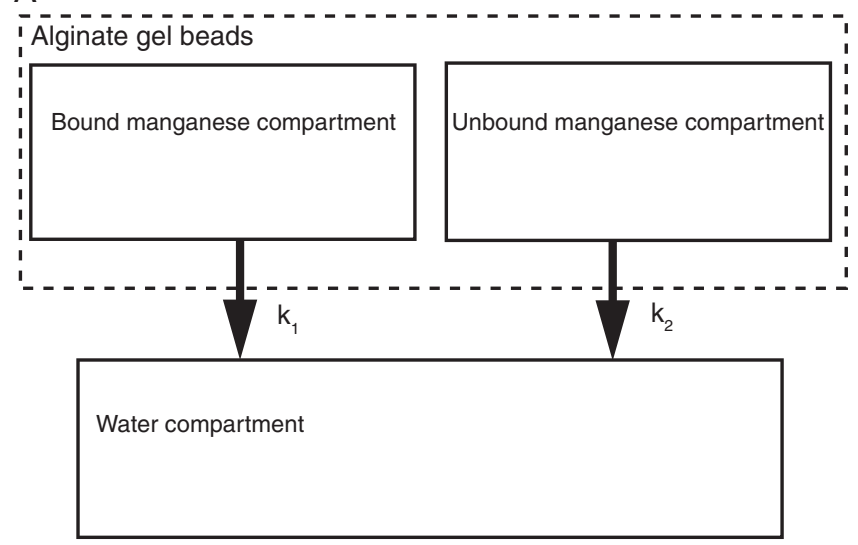

B

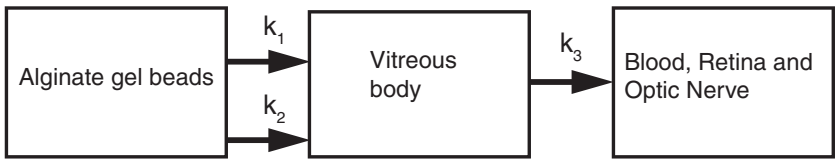

Figure 1. (A) The release of $\mathrm{Mn}^{2+}$ from alginate gel beads to the surrounding water during the MR experiment was described by a compartment model. We assumed both bound and unbound $\mathrm{Mn}^{2+}$ present in the alginate gel beads which were released with release rates $k_{1}$ and $k_{2}$, respectively. (B) Compartment model for simulation of intravitreal $\mathrm{Mn}^{2+}$ concentration. We assumed $\mathrm{Mn}^{2+}$ to be released with two release rate $\left(k_{1}\right.$ and $\left.k_{2}\right)$ from the alginate gel bead and into the vitreous body compartment, where it was cleared with the rate $k_{3}$. In a biological system the route of $\mathrm{Mn}^{2+}$ clearance from the vitreous body probably is by vascular transudation and anterograde transport within RGC axons. 


$$
\frac{\mathrm{d} Q_{3}}{\mathrm{~d} t}=k_{1} Q_{1}+k_{2} Q_{2}, \quad Q_{3}(0)=0
$$

Solving this set of simultaneous first-order linear differential equations [eqns (1)-(3)] yielded

$$
Q_{3}(t)=Q_{01}\left[1-\exp \left(-k_{1} t\right)\right]+Q_{02}\left[1-\exp \left(-k_{2} t\right)\right]
$$

If we assume all $\mathrm{Mn}^{2+}$ to be transferred to the water compartment, eqn (4) can be written:

$$
C(t)=C_{01}\left[1-\exp \left(-k_{1} t\right)\right]+C_{02}\left[1-\exp \left(-k_{2} t\right)\right]
$$

where $C(t)$ is the time-dependent $\mathrm{Mn}^{2+}$ concentration in the saline solution compartment, $C_{01}$ the contribution to the total concentration of $\mathrm{Mn}^{2+}$ from the bound $\mathrm{Mn}^{2+}$ compartment and $\mathrm{C}_{02}$ the contribution to the total concentration of $\mathrm{Mn}^{2+}$ in the saline solution compartment from the unbound $\mathrm{Mn}^{2+}$ compartment. Furthermore, the time constant for release was defined as $\tau_{i}=1 / k_{i}$ and a linear relationship between $\mathrm{Mn}^{2+}$ concentration and MR signal intensity (SI) approximated. In addition, the baseline signal from water was added to obtain a model of the time-dependent MEMRI signal:

$$
S(t)=S_{0}+S_{1}\left[1-\exp \left(-t / \tau_{1}\right)\right]+S_{2}\left[1-\exp \left(-t / \tau_{2}\right)\right]
$$

where $S_{0}$ is the baseline saline solution signal, $S_{1}$ and $S_{2}$ the portion of the signal caused by the total release of bound and unbound $\mathrm{Mn}^{2+}$, and $\tau_{1}$ and $\tau_{2}$ the time constants for release of $\mathrm{Mn}^{2+}$ from the bound and unbound $\mathrm{Mn}^{2+}$ compartments, respectively.

The MEMRI datasets were corrected for differences in receiver gain and reconstruction scaling. Dynamic SI curves were calculated from a ROI placed close to the rim of the container but excluding the alginate beads in each frame. The time constants for $\mathrm{Mn}^{2+}$ release were extracted by fitting the SI model [eqn (6)] to mean SI curves. To invalidate a bi-exponential model, a mono-exponential function was fitted to the data and compared with the bi-exponential fit. Curve extraction and data fitting was performed using in-house developed software and the Curve Fitting Toolbox ${ }^{\mathrm{TM}}$ (Matlab version 7.8.0, Mathworks Inc., Natick MA, USA). Confidence bounds of the estimated time constants were calculated within the Curve Fitting Toolbox ${ }^{\mathrm{TM}}$, which utilizes the inverse $\mathrm{R}$ factor from $\mathrm{QR}$ decomposition of the Jacobian, the degrees of freedom for error, and the root mean squared error.

\subsection{Simulation of ivit $\mathrm{Mn}^{2+}$ concentration}

A compartment model (Fig. 1B) was used to simulate the amount of $\mathrm{Mn}^{2+}$ in the vitreous body after ivit injection of a slow release contrast agent containing both bound and unbound $\mathrm{Mn}^{2+}$. We used the following equation to describe the rate of change of the amount of bound $\mathrm{Mn}^{2+}$ in the contrast agent:

$$
\frac{\mathrm{d} Q_{1}}{\mathrm{~d} t}=-k_{1} Q_{1}, \quad Q_{1}(0)=Q_{01}
$$

The rate of change of unbound $\mathrm{Mn}^{2+}$ in the contrast agent was described by:

$$
\frac{\mathrm{d} Q_{2}}{\mathrm{~d} t}=-k_{2} Q_{2}, \quad Q_{2}(0)=Q_{02}
$$

The rate of change of the amount of $\mathrm{Mn}^{2+}$ in the vitreous body, $Q_{v}$, was described by:

$$
\frac{\mathrm{d} Q_{v}}{\mathrm{~d} t}=k_{1} Q_{1}+k_{2} Q_{2}-k_{3} Q_{v}, \quad Q_{v}(0)=0
$$

where $k_{3}$ is the rate coefficient of $\mathrm{Mn}^{2+}$ vitreal clearance. This set of simultaneous first-order linear differential equations [eqns (7)-(9)] was solved to calculate the maximum ivit $\mathrm{Mn}^{2+}$ concentration.

The time constants $\tau_{1}=100 \mathrm{~min}$ and $\tau_{1}=600 \mathrm{~min}$ were used to characterize two slow-release contrast agents with different release rates. In both cases, release of unbound $\mathrm{Mn}^{2+}$ was described by the time constant $\tau_{2}=25 \mathrm{~min}$. The resulting timedependent ivit $\mathrm{Mn}^{2+}$ concentration was compared with a bolus injection. The time-dependent ivit $\mathrm{Mn}^{2+}$ concentration after a bolus injection was described by a mono-exponential decay function:

$$
C_{V}(t)=C_{01} \exp \left(-t / \tau_{3}\right)
$$

A time constant for vitreal clearance, $\tau_{3}=147 \mathrm{~min}$, was adapted from Olsen et al. (30). The maximum ivit $\mathrm{Mn}^{2+}$ concentration was calculated for cases where 20,80 and $100 \%$ of the initial amount of $\mathrm{Mn}^{2+}$ in the contrast agent was contained in the bound $\mathrm{Mn}^{2+}$ compartment.

\section{RESULTS}

\subsection{Binding of divalent ions to alginate}

Two naturally occurring alginates and three alginate samples of pure block composition were used to study both the binding of divalent ions in alginate gels and the stability of these hydrogels towards ion exchange, and hence $\mathrm{Mn}^{2+}$ release. In order to stabilize $\mathrm{Mn}$-alginate gels, combinations of $\mathrm{Mn}^{2+} / \mathrm{Ba}^{2+}$ and $\mathrm{Mn}^{2+} / \mathrm{Ca}^{2+}$ were used. As the stability of $\mathrm{Mn}$-alginate gels towards ion exchange in vivo will control the release rate of $\mathrm{Mn}^{2+}$, the dimensional swelling of gel beads in physiological saline was studied. The various gels investigated showed great differences with regard to stability (Table 1). Not surprisingly, an alginate with high content of $\mathrm{G}$ (high-G, 67\%) and with added $\mathrm{Ba}^{2+}$ in the gelling solution was found to be least susceptible to ion exchange. However, increasing the $G$ content to almost solely containing G-blocks (polyG, 88\%) did not improve the stability, but rather led to enhanced swelling. Gels of high-M and polyMG alginate all dissolved immediately in saline, indicating that, for these gels, most of the $\mathrm{Mn}^{2+}$ is released quickly in exchange for $\mathrm{Na}^{+}$. An alginate of pure mannuronic acid (polyM) did not form gels with either $\mathrm{Mn}^{2+} / \mathrm{Ca}^{2+}$, or $\mathrm{Mn}^{2+} / \mathrm{Ba}^{2+}$.

If $\mathrm{Mn}$-alginate is to be used for MEMRI purposes, not only the release rate of $\mathrm{Mn}^{2+}$, but also the total amount of $\mathrm{Mn}^{2+}$ conserved in the gel upon in vivo implantation, are of importance. Following the gelling of alginate, beads were quickly washed in saline and the gels analysed with regard to divalent ion content. The initial amount of $\mathrm{Mn}^{2+}$ in alginate gels was found to be quite constant regardless of the type of alginate and secondary ions used. The only exception to this is the combination of $\mathrm{Mn}^{2+}$ and $\mathrm{Ca}^{2+}$ in polyalternating alginate (polyMG) which in total contains a considerably lower amount of $\mathrm{Mn}^{2+}$ (see Table 2). The highest amount of divalent ions 


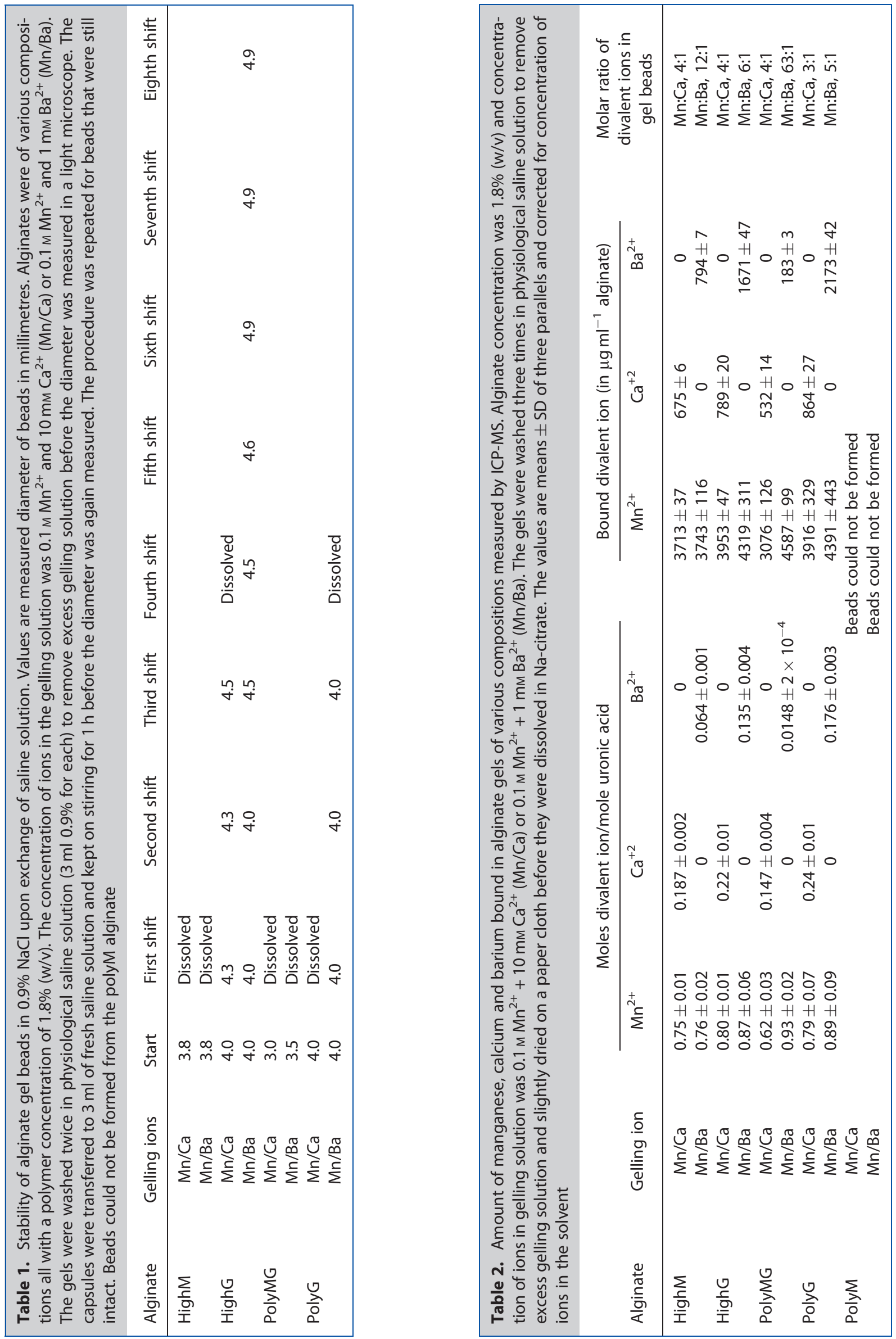


$\left(\mathrm{Mn}^{2+}\right.$ and $\left.\mathrm{Ca}^{2+} / \mathrm{Ba}^{2+}\right)$ conserved in the gel after a pre-washing step was found in alginates containing long $G$ blocks (polyG and high-G alginate).

To further investigate the binding of $\mathrm{Mn}^{2+}$ to the different block structures in alginate at a qualitative level, $C D$ was performed on blocks of G-, MG- and M residues (Fig. 2). Changes in the molar ellipticity upon addition of $\mathrm{Mn}^{2+}$ are observed in the CD spectra for G-blocks and MG-blocks, representing the formation of junctions (a higher degree of ordering of the chain) and hence a specific interaction of $\mathrm{Mn}^{2+}$ with the polymer. The $\mathrm{CD}$ spectra of polyM are in contrast unaffected by the additions of $\mathrm{Mn}^{2+}$, thus indicating a lack of interaction between $\mathrm{Mn}^{2+}$ and M-blocks in alginate.

If the binding of divalent ions to alginate results in complex formation, the addition of these ions to dilute alginate solutions will lead to an increase in viscosity. The effect of the additions of $\mathrm{Mn}^{2+}$ on the specific viscosity of polyM, polyMG and high-G alginate is given in Fig. 3 and compared with the additions of the non-gelling magnesium ion $\left(\mathrm{Mg}^{2+}\right)$. Although the differences are small, the gap between $\mathrm{Mg}^{2+}$ and $\mathrm{Mn}^{2+}$ seems to increase in the order polyM $<$ polyMG $<$ high-G.

Figure 4 illustrates that there are great macroscopic differences between Mn-alginate gels of different block structures. Gels of polyMG alginate were transparent and rigid, while all other alginate samples tested were turbid, soft gels. Gels
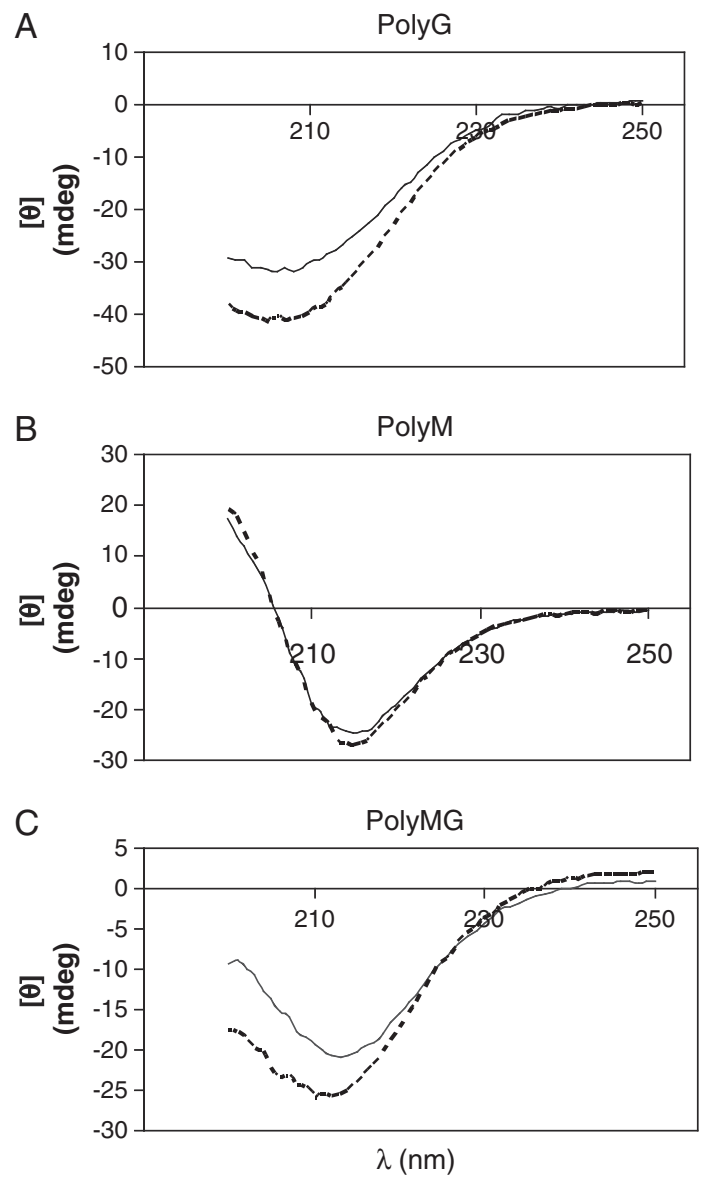

Figure 2. Circular dichroism spectra of (A) polyG, (B) polyM and (C) polyMG given as molar ellipticity as a function of wavelength before (dotted line) and after (continuous line) addition of $\mathrm{Mn}^{2+}$ (Mn/polymer repeating unit $=0.5$ ).
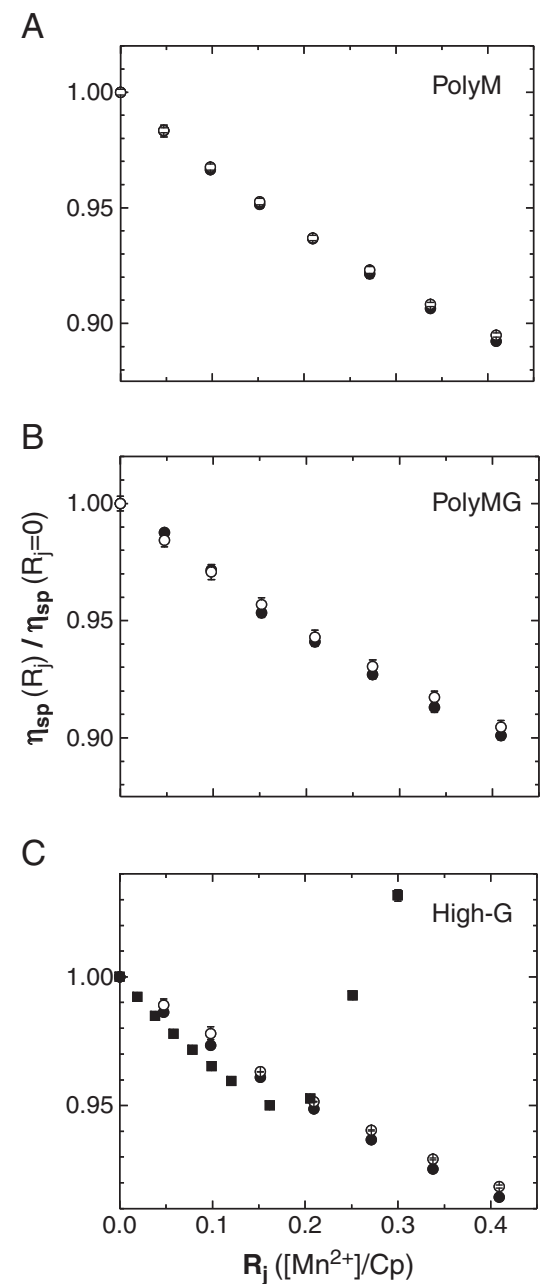

Figure 3. Relative variation of the specific viscosity upon addition of divalent ions $\left[\eta_{\mathrm{sp}}\left(R_{\mathrm{j}}\right)\right]$ with respect to the specific viscosity $\left[\eta_{\mathrm{sp}}\left(R_{\mathrm{j}}=0\right)\right]$ of $(\mathrm{A})$ polyM, (B) polyMG and (C) high-G. Legend: $(\bullet) \mathrm{Mn}^{2+},(\mathrm{O}) \mathrm{Mg}^{2+}$ and (๘) $\mathrm{Ca}^{2+}$.

containing high amounts of $\mathrm{G}$ residues (polyG and high-G) were milky white, whereas a high-M alginate was turbid.

\subsection{In vitro MEMRI using Mn-alginate}

In vitro MEMRI of all the different types of Mn-alginate beads revealed diverse profiles of release of $\mathrm{Mn}^{2+}$ from the beads over time (Figs 5 and 6). The dynamic changes of $\mathrm{Mn}^{2+}$ concentration in the surrounding water were contingent on $\mathrm{Mn}$-alginate bead type. This is illustrated in Fig. 5, which provides representative examples of controlled release of $\mathrm{Mn}^{2+}$ from polyMG $\mathrm{Ba} / \mathrm{Mn}$ and high-G $\mathrm{Ba} / \mathrm{Mn}$ alginate beads in saline at three different time points after washing. When $\mathrm{Mn}^{2+}$ was released from the alginate beads, the $\mathrm{Mn}^{2+}$ concentration in the surrounding water increased, shown as an increase in SI. However, high concentrations of $\mathrm{Mn}^{2+}$ can cause signal loss because of the $T_{2}$ effect and this was seen in the MEMRI of alginate gel beads at early time points. High-G Ba/Mn alginate retained a high concentration of $\mathrm{Mn}^{2+}$ for a longer period of time than the polyMG Ba/Mn sample, seen as prolonged hypointensity of the alginate gel beads (Fig. 5).

Figure 6 shows the best fit of the model [eqn (6)] to the dynamic MEMRI curves of the six different alginate beads. The bi-exponential model of $\mathrm{Mn}^{2+}$ release fitted the data well, but 

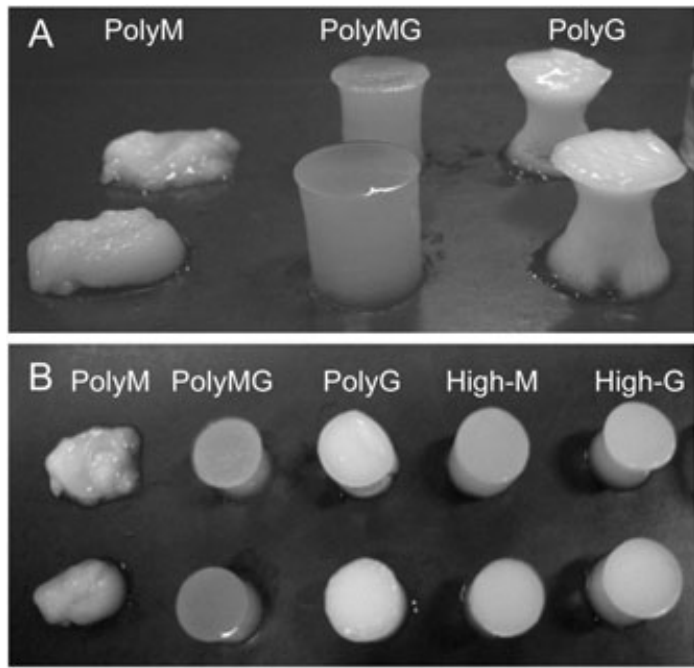

Figure 4. Appearance of $\mathrm{Mn}$-alginate gel cylinders. (A) Alginate samples representing the three block structures in alginate. From left: PolyM, polyMG and polyG. Back: $\mathrm{Mn} / \mathrm{Ca}$ alginate. Front: $\mathrm{Mn} / \mathrm{Ba}$ alginate. (B) Alginate cylinders of the various alginate samples (seen from above) used in the present study. From left: polyM, polyMG, polyG, high-M and high-G. Top: $\mathrm{Mn} / \mathrm{Ca}$ alginate. Bottom: $\mathrm{Mn} / \mathrm{Ba}$ alginate. $\mathrm{Mn}$-polyMG gels were transparent, strong gels, whereas Mn-polyG gels were milky white, very soft gels. PolyM alginate did not form stable hydrogels with manganese.

polyMG alginate with $\mathrm{Ba}^{2+}$ (Fig. 6D) seemed to release large amounts of $\mathrm{Mn}^{2+}$ fast, which resulted in a temporary local high concentration in the image plane early in the experiment. These data points were hence removed in the further model fitting. A mono-exponential function was inadequate to describe the fast increase in $\mathrm{SI}$, as the best fit gave large residuals for the early time points for all data sets (data not shown).
PolyMG Mn/Ba
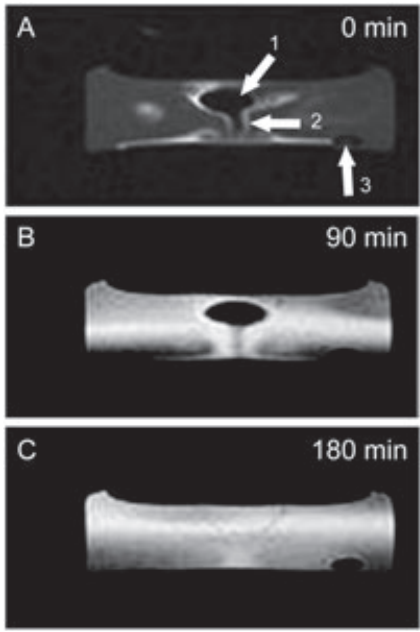

High-G Mn/Ba
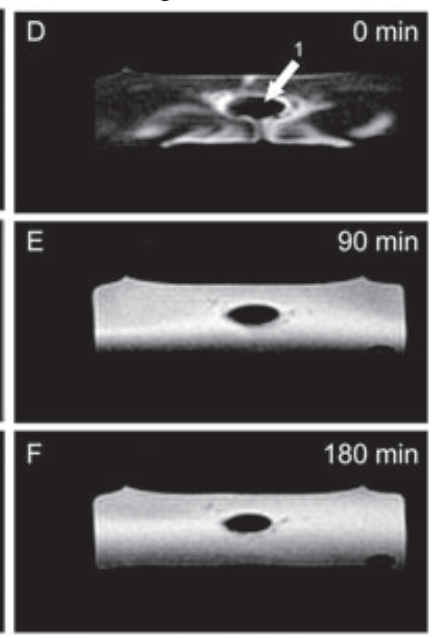

Figure 5. MRI of polyMG $\mathrm{Mn} / \mathrm{Ba}$-alginate $(\mathrm{A}-\mathrm{C}$ ) and high- $\mathrm{G} \mathrm{Mn} / \mathrm{Ba}-$ alginate (D-F) beads. The high concentration of $\mathrm{Mn}^{2+}$ in the alginate gel beads (1) caused signal loss ( $T_{2}$ effect) and rapidly released $\mathrm{Mn}^{2+}$ flowed downward from the alginate beads early in the experiment (2). After being distributed in the water, the $\mathrm{Mn}^{2+}$ concentration sank and caused hyper-intensity in the $T_{1}$-weighted images. Note how the $\mathrm{Mn}^{2+}$ concentration remained high in high-G $\mathrm{Mn} / \mathrm{Ba}$-alginate $(\mathrm{D}-\mathrm{F})$, whereas polyMG $\mathrm{Mn} / \mathrm{Ba}$-alginate seemed to release $\mathrm{Mn}^{2+}$ faster (A-C). The fluidtransfer line used for filling the glass vials is seen in the lower-right corner (3). The bead diameter was approximately $4 \mathrm{~mm}$.
Time constants extracted from the model fit (Fig. 6) are found in Table 3. The model fitting showed that $\mathrm{Mn}^{2+}$ was released with two distinct release rates: (i) a slow release rate, corresponding to a long time constant, $\tau_{1}$ and (ii), a fast release rate, corresponding to a short time constant, $\tau_{2}$. The short time constant $\left(\tau_{2}\right)$ varied marginally between the different groups. By contrast, $\tau_{1}$ values show great variation (100-700 min) between the groups in the order high- $\mathrm{G} \geq$ high-M $>$ polyMG, increasing upon using $\mathrm{Ba}^{2+}$ instead of $\mathrm{Ca}^{2+}$ as secondary ion.

The simulation of ivit $\mathrm{Mn}^{2+}$ concentration (Fig. 7E) showed that using slow release systems with time constants of 100 and 600 min effectively reduces the maximum ivit $\mathrm{Mn}^{2+}$ concentration. The time constant of $600 \mathrm{~min}$ reduced the maximum ivit $\mathrm{Mn}^{2+}$ concentration to 57,21 and $15 \%$ as the initial amount of bound $\mathrm{Mn}^{2+}$ in the contrast agent was set to 20,80 and $100 \%$, respectively. For the same initial amounts of bound $\mathrm{Mn}^{2+}$, the time constant of 100 min reduced the maximum ivit $\mathrm{Mn}^{2+}$ concentration to 63,46 and $44 \%$, respectively. These are significant reductions, considering that maximum ivit $\mathrm{Mn}^{2+}$ concentration derived from a bolus injection is $100 \%$ in vivo.

\subsection{In vivo MEMRI using Mn-alginate}

Proof of principle of optic nerve $\mathrm{Mn}^{2+}$ enhancement after $\mathrm{Mn}$ alginate bead injection was demonstrated by intravitreal (ivit) injection of high-G Mn/Ba-alginate beads in rats. Figure 7(A-D) shows significant enhancement of the retina, optic nerve and contralateral superior colliculus $24 \mathrm{~h}$ post-ivit injection.

\section{DISCUSSION}

\subsection{Binding and release of $\mathrm{Mn}^{2+}$}

If a controlled release system for $\mathrm{Mn}^{2+}$-enhanced MRI is to be designed, knowledge on the ion binding capacity to the different block structures in alginate is fundamental as it forms the basis for the choice of alginate and type of ions to be used. In the present study we indeed show that large variations in $\mathrm{Mn}^{2+}$ amount and release are observed for the various alginate gels. In particular, the binding of $\mathrm{Mn}^{2+}$ to pure MG sequences is noticeably different from the binding of other alginate samples (Fig. 4 and Table 2). By means of ${ }^{13}$ C-NMR spectroscopy Emmerichs et al. (1) have shown that $\mathrm{Mn}^{2+}$ binds to G-blocks in cavities between each pair of $\mathrm{G}$ residues in a similar manner to $\mathrm{Ca}^{2+}$, whereas the binding of $\mathrm{Mn}^{2+}$ to $\mathrm{M}$-blocks is primarily based on electrostatic attraction without forming stable complexes. Interestingly, in the case of MG-blocks, $\mathrm{Mn}^{2+}$ was found to bind specifically and preferentially in a complex owing to the pocket formed by the axial-equatorial link between the two monomers. The macroscopic difference between Mn-gels of polyalternating alginate (rigid and transparent) and alginates containing G-blocks (weak and turbid/white; Fig. 4) demonstrates the distinct binding of $\mathrm{Mn}^{2+}$ to MG-blocks. High turbidity and soft texture of gels is a characteristic feature of precipitates as typically seen in Ca-polymannuronate and indicates that the ion binding is not strong enough for the formation of a rigid gel (ordered structure) to be energetically favourable (36). From CD analysis of the three block structures (Fig. 2), there seems to be an interaction of $\mathrm{Mn}^{2+}$ with $\mathrm{G}$ blocks and, to some extent, with MG blocks, while the CD spectra of polyM are totally unaffected by the additions of the ion, which explains why gels of Mn-polyM alginate could not be formed. However, although the $C D$ spectra point towards 
A

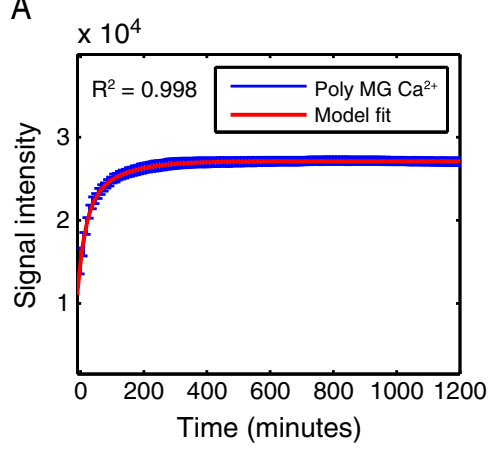

D

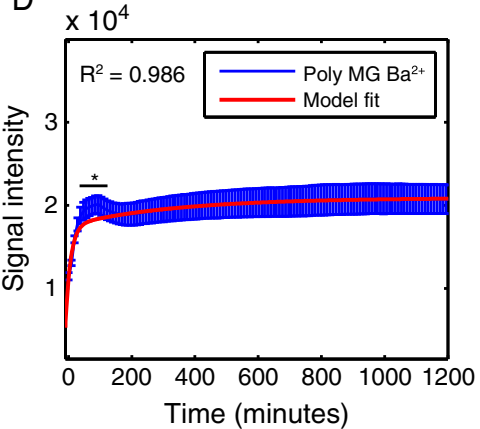

B

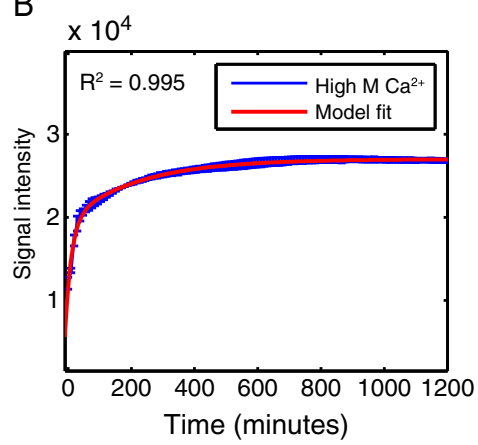

E

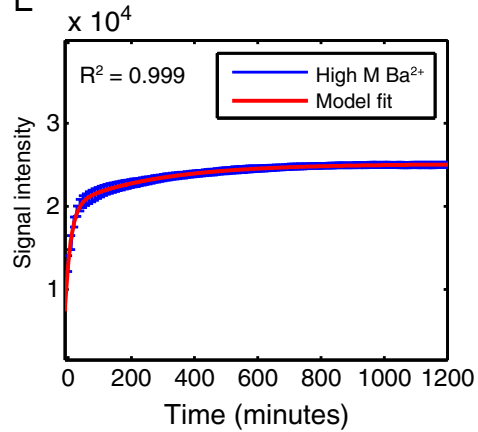

C

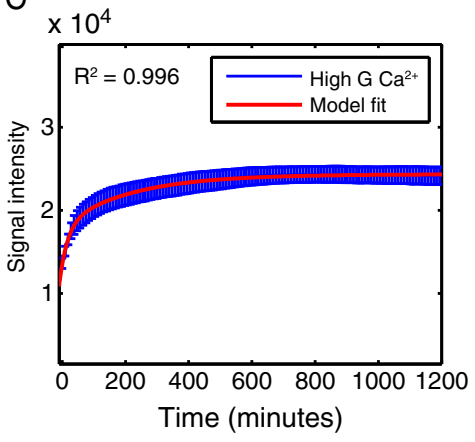

$\mathrm{F}$

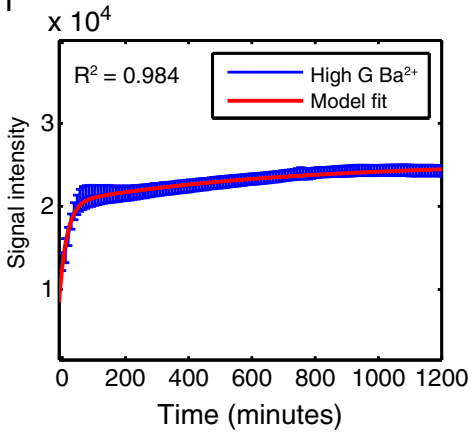

Figure 6. Dynamic MEMRI of (A) PolyMG Mn/Ca-alginate $(n=6)$, (B) high-M Mn/Ca-alginate $(n=2)$, (C) high-G Mn/Ca-alginate ( $n=5)$, (D) polyMG Mn/Ba-alginate $(n=2)$, (E) high-M Mn/Ba-alginate $(n=6)$ and (F) high-G Mn/Ba-alginate $(n=5)$. Error bars represent $\pm \mathrm{SE}$. The bi-exponential model fitted the data well except for $\mathrm{Mn}^{2+}$ release from polyMG $\mathrm{Mn} / \mathrm{Ba}(\mathrm{D})$ where data points between 47 and 141 min were removed from the fit $(*)$.

Table 3. Time constants (minutes) of $\mathrm{Mn}^{2+}$ release from high-G, high-M and polyMG alginate with either $\mathrm{Ca}^{2+}$ or $\mathrm{Ba}^{2+}$ as stabilizing ions. Values are extracted from bi-exponential fit to dynamic MEMRI (95\% confidence intervals in brackets)

\begin{tabular}{|c|c|c|c|c|c|c|c|}
\hline & & \multicolumn{2}{|c|}{ High-G } & \multicolumn{2}{|c|}{ High-M } & \multicolumn{2}{|c|}{ PolyMG } \\
\hline \multirow[t]{2}{*}{$\mathrm{Ca}^{2+}$} & $\tau_{1}$ & $219(209,229)$ & $n=5$ & $222(210,234)$ & $n=2$ & $106(99,113)$ & $n=6$ \\
\hline & $\tau_{2}$ & $25(22,28)$ & & $19(17,21)$ & & $24(22,26)$ & \\
\hline \multirow[t]{2}{*}{$\mathrm{Ba}^{2+}$} & $\tau_{1}$ & $677(555,799)$ & $n=5$ & $280(272,288)$ & $n=6$ & $342(294,390)$ & $n=2$ \\
\hline & $\tau_{2}$ & $23(21,25)$ & & $18(17,19)$ & & $16(14,18)$ & \\
\hline
\end{tabular}

interaction between the ion and the polymer, they do not give information on the nature of the interaction. An additional insight on the overall macromolecular properties of the alginate chain has been attempted by looking at the relative variation of the specific viscosity upon addition of the divalent ions (Fig. 3). The specific viscosity of a polyelectrolyte is strongly affected by the number and distribution of the fixed charges, as well as by their interaction with the mobile counterions. The reduction of the relative specific viscosity upon addition of $\mathrm{Mg}^{2+}$ can be interpreted as arising from a combined effect of the dilution of the polymer sample and of the condensation of the divalent cations causing a reduction of the effective charge density and hence a decrease of the polyuronate hydrodynamic volume. Figure 3 shows that the addition of $\mathrm{Mn}^{2+}$ ions to the alginate samples analysed leads to a similar trend. Nevertheless, the deviation of relative specific viscosity between $\mathrm{Mg}^{2+}$ and $\mathrm{Mn}^{2+}$ seems to increase in the order polyM $<$ polyMG $<$ high-G, thus supporting the $C D$ data. However, no alginate sample showed chain-chain association upon addition of $\mathrm{Mn}^{2+}$ ions. In fact, when $\mathrm{Ca}^{2+}$ ions are added to high-G alginate, a non-monotonic trend of the relative specific viscosity is noticed (Fig. 3C). This has been previously interpreted as an indication of interchain association and network formation (37).

While the findings by Emmerics et al. might explain the distinct nature of the Mn-polyMG gel, there is no evidence pointing to $\mathrm{Mn}^{2+}$ binding more strongly to alternating sequences, as the alginates with high proportions of MG sequences immediately destabilize in saline solution and result in fast release of $\mathrm{Mn}^{2+}$, indicating that $\mathrm{Mn}^{2+}$ is quickly exchanged with the non-gelling $\mathrm{Na}^{+}$(Tables 1 and 3 and Fig. 5).

In the present study the highest total amount of divalent ions conserved in the gel after a pre-washing step was, not surprisingly, found in polyG and high-G alginate. These alginates contain long continuous blocks of guluronic acid (G) residues having the highest affinity to divalent ions (38). For the same reason, these alginates are most stable towards swelling and dissolution in saline (Table 1), in particular in combination with $\mathrm{Ba}^{2+}$. Model fitting of the release rate of $\mathrm{Mn}^{2+}$ from alginate gels based on MRI scans results in the longest time constants (slowest release) for these gels, confirming our findings on gel stability and divalent ion content studies. However, increasing the G content to almost $90 \%$ did not enhance stability further, but 

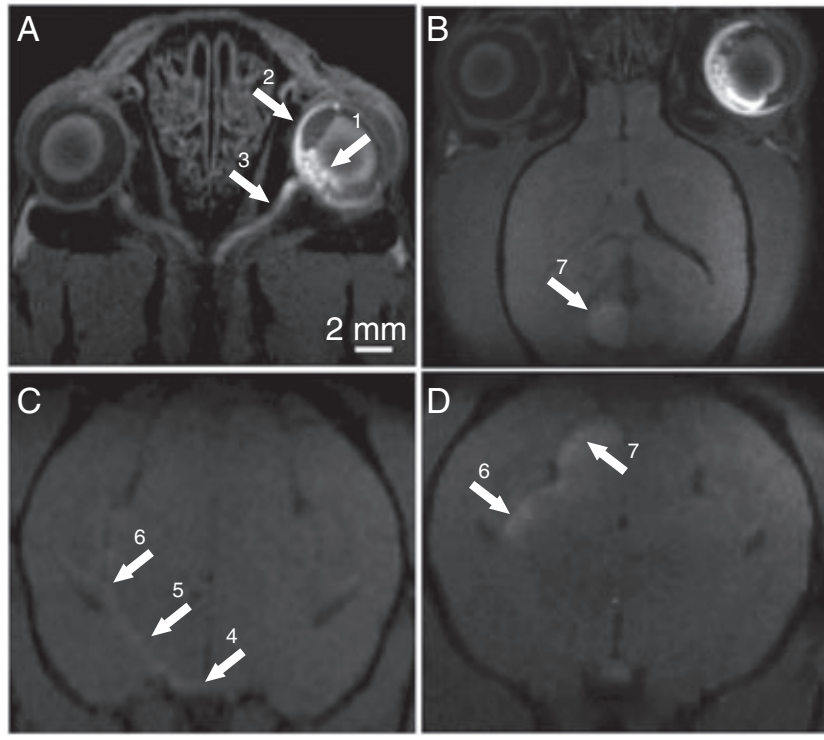

$\mathrm{E}$

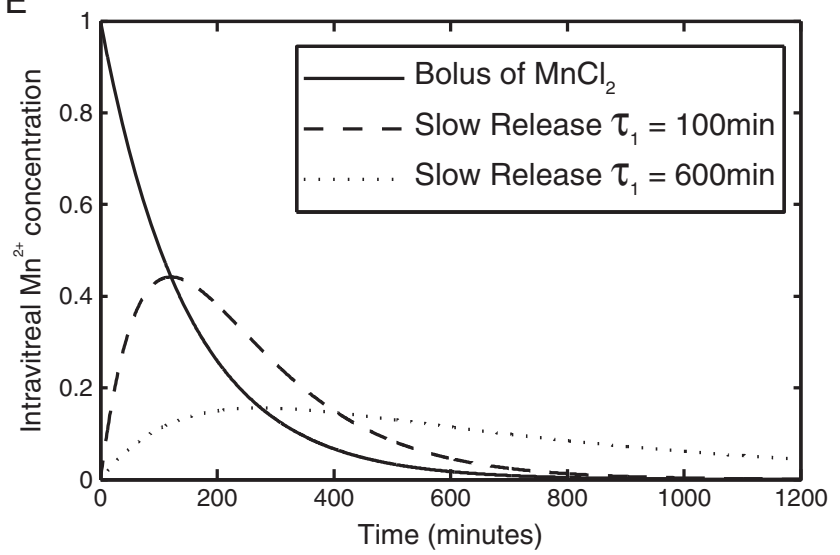

Figure 7. Oblique two-dimensional slices from the three-dimensional MEMRI volume showing the rat retina, optic nerve and contralateral superior colliculus $24 \mathrm{~h}$ after ivit injection of high-G Ba/Mn alginate beads (1). $\mathrm{Mn}^{2+}$ entered the retinal ganglion cells via their $\mathrm{Ca}^{2+}$ channels and caused hyperintense signal in the retina (2), optic nerve (3), optic chiasm (4) and further in the contralateral optic tract (5), geniculate nucleus (6) and superior colliculus (7). (E) Simulation of ivit $\mathrm{Mn}^{2+}$ concentration showed decreased maximum $\mathrm{Mn}^{2+}$ concentration as a function of increasing time constant for release. Furthermore, slow release increased the time $\mathrm{Mn}^{2+}$ were present in the vitreous body, which increases the time $\mathrm{Mn}^{2+}$ are available for retinal ganglion cell uptake in vivo.

rather led to the opposite effect, illustrating that a certain proportion of $\mathrm{M}$ and $\mathrm{MG}$ blocks is required for the formation of stable $\mathrm{Mn}$-alginate hydrogels.

\subsection{Effect of secondary stabilizing ions}

As $\mathrm{Mn}^{2+}$ alone is not sufficient to form a stable alginate hydrogel, secondary divalent ions with higher affinity to alginate must be used. From the present study it is evident that the type of divalent ion chosen for stabilization purposes influences the degree of gel stability to a large extent and can hence be used to manipulate both the amount and release rate of $\mathrm{Mn}^{2+}$ from the gel. When a combination of $\mathrm{Mn}^{2+}$ and $\mathrm{Ca}^{2+}$ is used for gelling a polyalternating alginate, $\mathrm{Ca}^{2+}$ will compete with $\mathrm{Mn}^{2+}$ because of the rather high specificity of $\mathrm{Ca}^{2+}$ to long alternating sequences and formation of MG/MG junctions $(2,39)$. However, as the binding is not strong (40), a large portion of ions (both $\mathrm{Mn}^{2+}$ and $\mathrm{Ca}^{2+}$ ) will be exchanged with $\mathrm{Na}^{+}$during the initial washing procedure of capsules, explaining the low total concentration of ions for this particular gel (Table 2).

The relatively long $\tau_{1}$ time constant achieved for polyMG alginate with $\mathrm{Ba}^{2+}$ deserves comment. $\mathrm{As}^{\mathrm{Ba}^{2+}}$ is found to bind poorly to polyMG alginate and hence not lead to increased gel stability, a shorter time constant would be expected. However, as our data show (Fig. 6D), $\mathrm{Mn}^{2+}$ concentration seems to increase followed by an initial decrease early in the experiment. This could be explained by rapid initial release owing to the very high content of poorly bound $\mathrm{Mn}^{2+}$, which causes local high concentration before $\mathrm{Mn}^{2+}$ are distributed in the water volume by diffusion. MR images obtained immediately upon immersion of the alginate beads into $\mathrm{NaCl}$ solution corroborate the above observation as they reveal dynamic changes in $T_{1}$ consistent with large-scale $\mathrm{Mn}-\mathrm{Na}$ ion exchange (Fig. 1). In order to describe the slow component of increased $\mathrm{Mn}^{2+}$ concentration, data between 47 and $141 \mathrm{~min}$ were excluded from the fit and our results may therefore not be representative for $\mathrm{Mn}^{2+}$ release from polyMG with $\mathrm{Ba}^{2+}$.

Another interesting observation is the large discrepancy between the $\mathrm{Mn}^{2+}: \mathrm{Ba}^{2+}$ and $\mathrm{Mn}^{2+}: \mathrm{Ca}^{2+}$ ratios in the gelling solutions (100:1 and 10:1, respectively) compared with the ratios of ions in the resulting gel beads (Table 2 ), reflecting the various affinities of ions to alginate. After gelling, the $\mathrm{Mn}^{2+}: \mathrm{Ca}^{2+}$ ratio was approximately the same for all types of alginates tested, and in all cases $\mathrm{Ca}^{2+}$ had accumulated in the gel compared with $\mathrm{Mn}^{2+}$, which was expected given the higher affinity of $\mathrm{Ca}^{2+}$ to alginate. In contrast, the $\mathrm{Mn}^{2+}: \mathrm{Ba}^{2+}$ ratio varied greatly among the alginates studied. The very highest $\mathrm{Mn}^{2+}: \mathrm{Ba}^{2+}$ ratio was found in the pure polyalternating sample, followed by high- $M$ alginate.

Furthermore, elemental analysis of these gels makes it evident (Table 2) that the amount of bound $\mathrm{Ba}^{2+}$ was extremely low compared with alginates with large amounts of $G$ residues. The very low amount of $\mathrm{Ba}^{2+}$ bound in gels of polyalternating alginate indicates poor affinity of $\mathrm{Ba}^{2+}$ to pure alternating sequences. This explains the limited binding of $\mathrm{Ba}^{2+}$ to high-M alginate, also rich in alternating sequences $\left(F_{\mathrm{GM}=\mathrm{MG}}=0.20\right)$. The lack of stability of these alginates in sodium chloride (Table 1 ) further confirms the above. The findings are consistent with our previous results that indicated poor binding of $\mathrm{Ba}^{2+}$ to alternating sequences (6).

\subsection{Controlled release of $\mathrm{Mn}^{2+}$ for in vivo MEMRI}

The model fitting showed that $\mathrm{Mn}^{2+}$ were released with two different release rates: a fast release rate corresponding to a short time constant and a slow release rate corresponding to a long time constant. The short time constant $\left(\tau_{2}\right)$ varied marginally between the different groups of alginate $\mathrm{Ba}^{2+} / \mathrm{Ca}^{2+}$ combinations and may be attributed to unbound $\mathrm{Mn}^{2+}$ precipitated by washing the alginate beads in $\mathrm{NaCl}$ prior to MRI data acquisition. Notwithstanding that the initial concentration of $\mathrm{Mn}^{2+}$ bound within the gels greatly varies between the different alginates (Table 2), such effects could be reduced by including additional washing steps into our protocol. The substantial longer time constant $\left(\tau_{1}\right)$ showed great variation between the groups in the order high-G $\geq$ high-M $>$ polyMG, increasing upon using $\mathrm{Ba}^{2+}$ instead of $\mathrm{Ca}^{2+}$ as secondary ion. As discussed above, this is consistent with the degree of gel stability of the different types 
of alginate and $\mathrm{Ba}^{2+} / \mathrm{Ca}^{2+}$ combinations. Hence, we interpret $\tau_{1}$ to be the time constant for release of bound $\mathrm{Mn}^{2+}$.

Ivit injection of $\mathrm{Mn}$-alginate gel beads in rats demonstrates the applicability of alginate gel beads as a slow release system for MEMRI of the CNS. MR image of rat retina, optic nerve and contralateral superior colliculus $24 \mathrm{~h}$ post ivit injection (Fig. 7A-D) illustrates that $\mathrm{Mn}^{2+}$ are indeed released from gel beads in exchange for sodium ions in the vitreous body. The $\mathrm{Mn}^{2+}$ are subsequently taken up by retinal ganglion cells (RGC) and transported anterogradely within their axons to the contralateral superior colliculus in the mid brain, similar to what has been demonstrated previously using ivit bolus injections of $\mathrm{MnCl}_{2}$ $(15,21,22)$. Simulation of the ivit $\mathrm{Mn}^{2+}$ concentration after $\mathrm{Mn}$ alginate bead injection (Fig. 7E) shows that a slow release system both reduces the maximum ivit $\mathrm{Mn}^{2+}$ concentration and increases the time during which $\mathrm{Mn}^{2+}$ are available for uptake by RGC. The latter is postulated to increase MR contrast in the $\mathrm{Mn}^{2+}$-enhanced optic nerve (30).

Previously, we have shown that intravitreal bolus injection of $150 \mathrm{nmol} \mathrm{MnCl}_{2}$ yields sufficient contrast at both 2.35 and $7.0 \mathrm{~T}$ $(21,22)$. However, longitudinal MEMRI studies that involve repeated intravitreal doses of $\mathrm{MnCl}_{2}$ carry the inherent risk of $\mathrm{Mn}^{2+}$-induced toxicity. Therefore, large reductions in the intravitreal $\mathrm{Mn}^{2+}$ can be expected to significantly eliminate potential long-term toxic effects of repeated intravitreal bolus injections of $\mathrm{Mn}^{2+}$ on RGC neurons. Based on the findings of our model, we predict that utilization of tailored $\mathrm{Mn}$-alginate beads may achieve reductions of ivit $\mathrm{Mn}^{2+}$ concentrations of up to $\sim 85 \%$.

Previous work by our group (30) concluded that there is a plateau of maximum $\mathrm{Mn}^{2+}$ entry into neurons, suggesting that signal enhancement is contingent on the duration of $\mathrm{Mn}^{2+}$ availability rather than on $\mathrm{Mn}^{2+}$ dose. Thus, a very important finding in our study is that the slow release mechanism utilizing $\mathrm{Mn}$-alginate beads significantly increases the duration of intravitreal $\mathrm{Mn}^{2+}$ availability for uptake by RGC neurons.

The MR $T_{1}$ contrast obtained in our study using the $\mathrm{Mn}$-alginate beads was equivalent to the contrast obtained in previous studies using intravitreal bolus injection of $\mathrm{MnCl}_{2}$ $(21,22,30,41)$. However, a thorough investigation and comparison of bolus injections vs $\mathrm{Mn}$-alginate beads in terms of $T_{1}$ signal enhancement was beyond the scope of this study, but constitutes one of our future research priorities.

In our model of $\mathrm{Mn}^{2+}$ release and subsequent increase of $\mathrm{SI}$ in the surrounding water [eqn (6)], we approximated a linear relationship between $\mathrm{SI}$ and $\mathrm{Mn}^{2+}$ concentration, which is not true for large variations. As $\mathrm{Mn}^{2+}$ concentrations gradually increase, the $\mathrm{SI}$ tends to underestimate $\mathrm{Mn}^{2+}$ concentration and this may have introduced errors in the time constant estimates. However, we believe this to be a systematic error, not interfering with our general conclusions on $\mathrm{Mn}^{2+}$ release between the different groups. Future studies should consider time-resolved $T_{1}$-mapping for direct measurement of $\mathrm{Mn}^{2+}$ concentration.

In both of our compartment models (Fig. 1) we have assumed a concentration-dependent release of $\mathrm{Mn}^{2+}$ from the alginate gel beads [eqns (1) and (7)]. In alginate gel, bound $\mathrm{Mn}^{2+}$ are released in exchange for $\mathrm{Na}^{+}$and are thus dependent on the concentration of the latter. In a closed system, as represented here by an immersed alginate gel in a container, our model seems to be adequate, but in a biological system the supply of $\mathrm{Na}^{+}$may be different and our assumption may not be true. However, we believe that our simulation of ivit $\mathrm{Mn}^{2+}$ concentration clearly demonstrates the potential of reducing $\mathrm{Mn}^{2+}$ concentration by use of tailored alginates for slow release of contrast agents.

\section{CONCLUSIONS}

In the present study we provide proof of concept for Mn-alginate gel beads as potential candidates for slow release of $\mathrm{Mn}^{2+}$ in MEMRI applications. Manganese binds to various extents to the different blocks of alginate and the stability of $\mathrm{Mn}$-alginate gels can be further controlled using various secondary ions. Hence, the total amount of manganese in gels as well as the release rate of $\mathrm{Mn}^{2+}$ out of gels can be controlled by the choice of alginates and combination of ions. A high-G Mn-alginate stabilized with $\mathrm{Ba}^{2+}$ will result in a gel which is stable towards ion exchange and resulting in slow release of manganese, whereas high-M or high-MG alginates will give the opposite. This study can hence form the basis for designing systems for controlled release of $\mathrm{Mn}^{2+}$ for MEMRI. Such systems can be tailored to meet specific bioanatomical/biophysical properties of different neuronal populations and experimental models in terms of $\mathrm{Mn}^{2+}$ uptake, transport and clearance, while they can be expected to enable significant refinement of the MEMRI technique for safe, nontoxic, serial application in longitudinal studies of CNS damage and repair. Further in vivo studies of $\mathrm{Mn}^{2+}$ release from alginate capsules constitute a natural progression of our research.

\section{Acknowledgements}

The Norwegian Research Council is thanked for funding this work (FUGE MIC Trondheim, Biopolymer Engineering, and a personal grant to Y.A.M.). Y.A.M. further wishes to acknowledge the Chicago Diabetes Project for partly funding the research on ion binding. I.S. wishes to acknowledge funding in support of this work provided by the Medical Imaging Laboratory (MI Lab), Centre for Research-based Innovation, NTNU. The authors are grateful to Dr Berit Strand for fruitful discussions, early planning of experiments and for reading the manuscript. We thank Tina Bugge Pedersen for excellent technical assistance.

\section{REFERENCES}

1. Emmerichs N, Wingender J, Flemming HC, Mayer C. Interaction between alginates and manganese cations: identification of preferred cation binding sites. Int J Biol Macromol 2004; 34(1-2): 73-79.

2. Donati I, Holtan S, Mørch YA, Borgogna M, Dentini M, Skjåk-Bræk G. New hypothesis on the role of alternating sequences in calciumalginate gels. Biomacromolecules 2005; 6(2): 1031-1040.

3. Donati I, Asaro F, Paoletti S. Experimental evidence of counterion affinity in alginates: the case of nongelling ion $\mathrm{Mg}^{2+}$. J Phys Chem B 2009; 113(39): 12877-12886.

4. Haug A, Smidsrød O. Selectivity of some anionic polymers for divalent metal ions. Acta Chem Scand 1970; 24: 843-854.

5. Haug A. The affinity of some divalent metals to different types of alginates. Acta Chem Scand 1961; 15: 1794-1795.

6. Mørch YA, Donati I, Strand BL, Skjåk-Bræk G. Effect of $\mathrm{Ca}^{2+}, \mathrm{Ba}^{2+}$ and $\mathrm{Sr}^{2+}$ on alginate microbeads. Biomacromolecules 2006; 7(5): 1471-1480.

7. Grant GT, Morris ER, Rees DA, Smith PJC, Thom D. Biological interactions between polysaccharides and divalent cations: the egg-box model. FEBS Lett 1973; 32(1): 195-198.

8. Wang ZY, Zhang QZ, Konno M, Saito S. Sol-gel transition of alginate solution by the addition of various divalent-cations - C-13-NMR spectroscopic study. Biopolymers 1993; 33(4): 703-711. 
9. Martinsen A, Skjåk-Bræk G, Smidsrød O. Alginate as immobilization material: I. Correlation between chemical and physical properties of alginate gel beads. Biotechnol Bioeng 1989; 33: 79-89.

10. Thu B, Bruheim P, Espevik T, Smidsrød O, Soon-Shiong P, Skjåk-Bræk G. Alginate polycation microcapsules. II. Some functional properties. Biomaterials 1996; 17: 1069-1079.

11. Darrabie MD, Kendall WF, Opara EC. Effect of alginate composition and gelling cation on micro-bead swelling. J Microencapsul 2006; 23(1): 29-37.

12. Zimmermann $\mathrm{H}$, Ehrhart $\mathrm{F}$, Zimmermann $\mathrm{D}$, Muller $\mathrm{K}$, Katsen-Globa A, Behringer M, Feilen PJ, Gessner P, Zimmermann G, Shirley SG, Weber MM, Metze J, Zimmermann U. Hydrogel-based encapsulation of biological, functional tissue: fundamentals, technologies and applications. Appl Phys A Mater Sci Process 2007; 89(4): 909-922.

13. Narita K, Kawasaki F, Kita H. Mn and Mg influxes through Ca channels of motor-nerve terminals are prevented by verapamil in frogs. Brain Res 1990; 510(2): 289-295.

14. Sloot WN, Gramsbergen JBP. Axonal-transport of manganese and its relevance to selective neurotoxicity in the rat basal ganglia. Brain Res 1994; 657(1-2): 124-132.

15. Pautler RG, Silva AC, Koretsky AP. In vivo neuronal tract tracing using manganese-enhanced magnetic resonance imaging. Magn Reson Med 1998; 40(5): 740-748.

16. Watanabe T, Frahm J, Michaelis T. Functional mapping of neural pathways in rodent brain in vivo using manganese-enhanced three-dimensional magnetic resonance imaging. NMR Biomed 2004; 17(8): 554-568.

17. Aoki I, Wu YJL, Silva AC, Lynch RM, Koretsky AP. In vivo detection of neuroarchitecture in the rodent brain using manganese-enhanced MRI. Neuroimage 2004; 22(3): 1046-1059.

18. Aoki I, Tanaka C, Takegami T, Ebisu T, Umeda M, Fukunaga M, Fukuda K, Silva AC, Koretsky AP, Naruse S. Dynamic activity-induced manganese-dependent contrast magnetic resonance imaging (DAIM MRI). Magn Reson Med 2002; 48(6): 927-933.

19. Weng JC, Chen JH, Yang PF, Tseng WYI. Functional mapping of rat barrel activation following whisker stimulation using activityinduced manganese-dependent contrast. Neuroimage 2007; 36(4): $1179-1188$.

20. Takeda A, Kodama Y, Ishiwatari S, Okada S. Manganese transport in the neural circuit of rat CNS. Brain Res Bull 1998; 45(2): 149-152.

21. Thuen M, Berry M, Pedersen TB, Goa PE, Summerfield M, Haraldseth $\mathrm{O}$, Sandvig A, Brekken C. Manganese-enhanced MRI of the rat visual pathway: Acute neural toxicity, contrast enhancement, axon resolution, axonal transport, and clearance of $\mathrm{Mn}^{2+}$. J Magn Reson Imag 2008; 28(4): 855-865.

22. Thuen $M$, Singstad TE, Pedersen TB, Haraldseth $O$, Berry $M$, Sandvig A, Brekken C. Manganese-enhanced MRI of the optic visual pathway and optic nerve injury in adult rats. J Magn Reson Imag 2005; 22(4): 492-500.

23. Saleem KS, Pauls JM, Augath $M$, Trinath $T$, Prause BA, Hashikawa $T$, Logothetis NK. Magnetic resonance imaging of neuronal connections in the macaque monkey. Neuron 2002; 34(5): 685-700.

24. Thuen $M$, Olsen $\varnothing$, Berry $M$, Pedersen TB, Kristoffersen A, Haraldseth $\mathrm{O}$, Sandvig A, Brekken C. Combination of $\mathrm{Mn}^{2+}$-enhanced and diffusion tensor mr imaging gives complementary information about injury and regeneration in the adult rat optic nerve. J Magn Reson Imag 2009; 29(1): 39-51.
25. Olsen $\varnothing$, Thuen M, Berry M, Kovalev V, Petrou M, Goa PE, Sandvig A, Haraldseth $\mathrm{O}$, Brekken $\mathrm{C}$. Axon tracing in the adult rat optic nerve and tract after intravitreal injection of MnDPDP using a semiautomatic segmentation technique. J Magn Reson Imag 2008; 27(1): 34-42.

26. Van der Linden A, Van Meir V, Tindemans I, Verhoye M, Balthazar J. Applications of manganese-enhanced magnetic resonance imaging (MEMRI) to image brain plasticity in song birds. NMR Biomed 2004; 17(8): 602-612.

27. van der Zijden JP, Wu O, van der Toorn A, Roeling TP, Bleys $R$, Dijkhuizen RM. Changes in neuronal connectivity after stroke in rats as studied by serial manganese-enhanced MRI. Neuroimage 2007; 34(4): 1650-1657.

28. Tucciarone J, Chuang KH, Dodd SJ, Silva A, Pelled G, Koretsky AP. Layer specific tracing of corticocortical and thalamocortical connectivity in the rodent using manganese enhanced MRI. Neuroimage 2009; 44(3): 923-931.

29. Brouillet EP, Shinobu L, McGarvey U, Hochberg F, Beal MF. Manganese injection into the rat striatum produces excitotoxic lesions by impairing energy-metabolism. Exp Neurol 1993; 120(1): 89-94.

30. Olsen $\varnothing$, Kristoffersen A, Thuen M, Sandvig A, Brekken C, Haraldseth $\mathrm{O}$, Goa PE. Manganese transport in the rat optic nerve evaluated with spatial- and time-resolved magnetic resonance imaging. J Magn Reson Imag 2010; 32: 551-560.

31. Santamaria AB. Manganese exposure, essentiality and toxicity. Indian J Med Res 2008; 128(4): 484-500.

32. Ding DL, Roth J, Salvi R. Manganese is toxic to spiral ganglion neurons and hair cells in vitro. Neurotoxicology 2011;32(2): 233-241.

33. Gimmestad $M$, Sletta $H$, Ertesvåg $H$, Bakkevig $K$, Jain $S$, Suh $S$, Skjåk-Bræk G, Ellingsen TE, Ohman DE, Valla S. The Pseudomonas fluorescens AlgG protein, but not its mannuronan C-5-epimerase activity, is needed for alginate polymer formation. J Bacteriol 2003; 185(12): 3515-3523.

34. Holtan S, Bruheim P, Skjåk-Bræk G. Mode of action and subsite studies of the guluronan block forming mannuronan C-5 epimerase AlgE1 and AlgE6. Biochem J 2006; 395: 319-329.

35. Haug A, Larsen B, Smidsrød O. Uronic acid sequence in alginate from different sources. Carbohydr Res 1974; 32(2): 217-225.

36. Smidsrød O, Haug A. Properties of poly(1,4-hexuronates) in the gel state. II. Comparison of gels of different chemical composition. Acta Chem Scand 1972; 26: 79-88.

37. Fang YP, Al-Assaf S, Phillips GO, Nishinari K, Funami T, Williams PA, Li LB. Multiple steps and critical behaviors of the binding of calcium to alginate. J Phys Chem B 2007; 111(10): 2456-2462.

38. Smidsrød O. Molecular basis for some physical properties of alginates in the gel state. J Chem Soc Faraday Trans 1974; 57: 263-274.

39. Mørch YA, Donati I, Strand BL, Skjåk-Bræk G. Molecular engineering as an approach to design new functional properties of alginate. Biomacromolecules 2007; 8(9): 2809-2814.

40. Donati I, Mørch YA, Strand BL, Skjåk-Bræk G, Paoletti S. Effect of elongation of alternating sequences on swelling behavior and large deformation properties of natural alginate gels. J Phys Chem B 2009; 113(39): 12916-12922.

41. Sandvig A, Sandvig I, Berry M, Olsen $\varnothing$, Pedersen TB, Brekken C, Thuen M. Axonal tracing of the normal and regenerating visual pathway of mouse, rat, frog, and fish using manganese-enhanced magnetic resonance imaging (MEMRI). J Magn Reson Imag 2011; 34(3): 670-675. 